\title{
Reconstructive trends and complications following parotidectomy: incidence and predictors in 11,057 cases
}

\author{
Cory Donovan Bovenzi ${ }^{*} \mathbb{D}$, Peter Ciolek, Meghan Crippen, Joseph M. Curry, Howard Krein and Ryan Heffelfinger
}

\begin{abstract}
Background: Parotidectomy is a common treatment option for parotid neoplasms and the complications associated with this procedure can cause significant morbidity. Reconstruction following parotidectomy is utilized to address contour deformity and facial nerve paralysis. This study aims to demonstrate national trends in parotidectomy patients and identify factors associated with adverse postoperative outcomes. This study includes the largest patient database to date in determining epidemiologic trends, reconstructive trends, and prevalence of adverse events following parotidectomy.

Methods: A retrospective review was performed for parotidectomies included in the ACS-NSQIP database between January 2012 and December 2017. CPT codes were used to identify the primary and secondary procedures performed. Univariate and multivariate analysis was utilized to determine associations between pre- and perioperative variables with patient outcomes. Preoperative demographics, surgical indications, and common medical comorbidities were collected. CPT codes were used to identify patients who underwent parotidectomy with or without reconstruction. These pre- and perioperative characteristics were compared with 30-day surgical complications, medical complications, reoperation, and readmission using uni- and multivariate analyses to determine predictors of adverse events.
\end{abstract}

Results: There were 11,057 patients who underwent parotidectomy. Postoperative complications within 30 days were uncommon (1.7\% medical, 3.8\% surgical), with the majority of these being surgical site infection (2.7\%). Free flap reconstruction, COPD, bleeding disorders, smoking, and presence of malignant tumor were the strongest independent predictors of surgical site infection. Readmission and reoperation were uncommon at an incidence of $2.1 \%$ each. The strongest factors predictive of readmission were malignant tumor and corticosteroid usage. The strongest factors predictive of reoperation were free flap reconstruction, malignant tumor, bleeding disorder, and disseminated cancer. Surgical volume/contour reconstruction was relatively uncommon (18\%). Facial nerve sacrifice was uncommon (3.7\%) and, of these cases, only $25.5 \%$ underwent facial nerve reinnervation and $24.0 \%$ underwent facial reanimation.

Conclusions: There are overall low rates of complications, readmissions, and reoperations following parotidectomy. However, certain factors are predictive of adverse postoperative events and this data may serve to guide management and counseling of patients undergoing parotidectomy. Concurrent reconstructive procedures are not commonly reported which may be due to underutilization or underreporting.

Keywords: Parotidectomy, Complications, Facial nerve, NSQIP, Reconstruction, Epidemiology, Readmission, Contour, Comorbidities, Infection

\footnotetext{
* Correspondence: cdb013@jefferson.edu

Thomas Jefferson University Hospital Department of Otolaryngology- Head

and Neck Surgery, 925 Chestnut Street, 6th Floor, Philadelphia, PA ,19107,

USA
}

(c) The Author(s). 2019 Open Access This article is distributed under the terms of the Creative Commons Attribution 4.0 International License (http://creativecommons.org/licenses/by/4.0/), which permits unrestricted use, distribution, and reproduction in any medium, provided you give appropriate credit to the original author(s) and the source, provide a link to the Creative Commons license, and indicate if changes were made. The Creative Commons Public Domain Dedication waiver (http://creativecommons.org/publicdomain/zero/1.0/) applies to the data made available in this article, unless otherwise stated. 


\section{Background}

Parotid neoplasms are rare entities which comprise less than $3 \%$ of head and neck tumors. Management is primarily surgical, and depending on the extent and severity of disease, ranges from a superficial parotidectomy to a radical parotidectomy with facial nerve sacrifice [1]. There is ample data pertaining to site specific morbidity following parotidectomy (e.g. facial nerve weakness, salivary fistula, and Frey's syndrome); however, the literature on general postoperative surgical morbidity following parotidectomy is lacking [2].

In the era of quality metrics, there is an ever-growing focus on improving surgical and postsurgical care, while reducing complications and cost. In 2001, The American College of Surgeons (ACS) piloted the first iteration of the National Surgical Quality Improvement Program (NSQIP) in the private hospital sector. The NSQIP database collects over 130 patient variable including preoperative risk factors, intraoperative variables, and postoperative complications. This data can be used by hospitals to track, analyze, and compare the quality of surgical care in a risk-adjusted manner. Currently, over 700 hospitals including 8 of the top 10 hospitals as ranked by the US News \& world report participate in the program $[3,4]$.

Currently, the majority of literature pertaining to the outcomes and trends in parotidectomy are limited to single institution or small multi-institutional studies. Our investigation aims to provide a reference for national trends in parotidectomy surgery including patient demographics, pre-operative comorbidities, operative variables, and postoperative outcomes.

\section{Methods}

\section{Data and study cohort}

This is a retrospective analysis of the parotidectomy cases using the NSQIP participant user files from January 2012 through December 2017. The database was queried for all cases with the following Current Procedural Terminology (CPT) codes: 42410, 42,415, 42,420, 42,425, and 42,426. The resultant cohort was characterized by rates of patient characteristics, comorbidities, operative characteristics, and 30-day postoperative complications.

\section{Patient characteristics}

Patient demographics examined included age, sex, and race. The indication for parotidectomy was elicited using the International Classification of Disease (ICD) version 9 or 10 code given for postoperative diagnosis and grouped into five major categories: malignant tumor, benign tumor, tumor not otherwise specified (NOS), other disease of parotid, and unclassified (Additional file 1 Table S1). Comorbidities defined by NSQIP include smoking (within the year prior to admission), weight loss (>10\% body weight in the 6 months prior to surgery), hypertension (requiring medication), dyspnea (on exertion or at rest), corticosteroid use (<30 days prior to surgery), surgical site infection, non-independent functional status, and a number of additional preexisting medical conditions [5]. Obesity was defined as BMI (body mass index) $>30$, derived from height and weight variables.

\section{Operative characteristics}

Cases were further analyzed for operative characteristics. Variables including inpatient versus outpatient status, surgical specialty performing the parotidectomy (otolaryngology- head and neck surgery, general surgery, plastic surgery, and other), and total operative time were directly defined by NSQIP [5]. The principal parotidectomy CPT code was used to determine procedure extent (total vs. superficial) and management of the facial nerve (not dissected, dissected and preserved, sacrificed, and unknown). Additionally using CPT codes, rates of concurrent procedures were examined such as neck dissection, nerve monitoring, free flap, other volume restoration, reinnervation, and reanimation. Procedure type and associated CPT codes are given in Additional file 1 Table S1.

\section{Outcome variables}

Operative outcomes were assessed including rates of 30day surgical complications, medical complications, reoperation, readmission, and length of hospital stay. Specific surgical complications include superficial surgical site infection (SSI), deep SSI (defined as "deep" or "organ space" SSI), wound dehiscence, and hemorrhage/hematoma formation. Specific medical complications include cardiac arrest, myocardial infarction, stroke, ventilator requirement $>48 \mathrm{~h}$, pneumonia, and various others enumerated in Table 3.

All complication variables were coded by NSQIP [5] with the exception of hemorrhage/hematoma, which was derived from the relevant ICD-9 and 10 codes given for readmission or reoperation diagnosis (Additional file 1 Table S1). The occurrence of this complication therefore refers to cases requiring reoperation or readmission for postoperative hemorrhage or hematoma formation within 30 days of the principal procedure.

\section{Statistical analysis}

Descriptive statistics were used to summarize by rates of patient characteristics, comorbidities, operative characteristics, and 30-day postoperative complications across the study cohort. In order to identify the patient and procedure characteristics associated with an increased risk for postoperative morbidity, binary logistic regression was performed. A regression model was generated to account for patient demographics, comorbidities, procedure extent, indication, setting, surgical specialty, and concurrent procedures. All comorbidities occurring at a rate of $\geq 0.5 \%$ of the overall cohort were included. Cases 
with unknown values were excluded, leaving 8811 cases for analysis. Regression analysis was performed for each complication occurring at a rate of $\geq 0.5 \%$, including wound dehiscence, surgical site infection, hemorrhage/ hematoma, overall surgical and medical complications, readmission, and reoperation. All variables found to be significantly associated with each of these complications are listed in Table 4.

All statistical analyses were performed using SPSS (Statistical Package for the Social Sciences), version 23 (IBM, Armok, NY). $P$-values of $<0.05$ were considered to be statistically significant. This analysis was determined to be exempt from Institutional Review Board approval due to the de-identified nature of the dataset.

\section{Results}

A total of 11,057 patients were identified as having undergoing parotidectomy between January 1, 2012 and December 31, 2017. Of these patients, the majority were male (53.0\%), white (70.4\%), and ages 61-70 (26.6\%). In this cohort, parotidectomy was most commonly performed for benign neoplasms (45.2\%), followed by malignant neoplasms (29.7\%) and tumors of uncertain significance (13.0\%). Parotidectomy was indicated for non-neoplastic disease (e.g. chronic parotitis) in $8.8 \%$ of cases. Examination of various patient comorbidities found hypertension (45.4\%), obesity (39.7\%), and smoking $(23.5 \%)$ to be most common (Table 1). Patients undergoing parotidectomy for benign lesions were significantly more likely to be smokers compared to those undergoing parotidectomy for malignant lesions (30.5\% vs. $13.9 \%, p<0.001)$. This may represent a preponderance of Warthin's tumors in smokers.

In this cohort, superficial parotidectomy was performed 2.4 times more frequently than total parotidectomy. Concurrent neck dissection was performed in $19.9 \%$ of cases. Reconstruction involving volume restoration was performed in $12.4 \%$ of cases, including free flaps (3.6\%), local flaps (5.4\%), fat/dermal grafts (2.0\%), and allografts (1.8\%) (Table 2). Total parotidectomy cases were significantly more likely to involve a concurrent volume restoration procedure compared to superficial parotidectomy $(17.8 \%$ vs. $10.3 \%, p<0.001)$. Facial nerve sacrifice was recorded in $3.7 \%$ of cases (Table 2). In this subset of patients, $25.5 \%$ underwent a concurrent reinnervation procedure, and $24.0 \%$ underwent a concurrent reanimation procedure (Table 2).

Overall, $5.1 \%$ of patients experienced a postoperative complication within 30 days of the procedure. The majority were surgical complications, occurring in $3.8 \%$ of patients. Surgical site infection occurred most commonly, with $1.9 \%$ developing a superficial SSI, and $0.8 \%$ of patients developing a deep SSI. Unplanned reoperation was observed in $2.1 \%$ of cases. Medical complications occurred
Table 1 Demographics and Patient Characteristics

\begin{tabular}{|c|c|c|}
\hline & $\mathrm{N}$ & $\%$ \\
\hline \multicolumn{3}{|l|}{ Age } \\
\hline$<50$ & 2772 & 25.3 \\
\hline $51-60$ & 2389 & 21.6 \\
\hline $61-70$ & 2920 & 26.6 \\
\hline $71-80$ & 1977 & 18.0 \\
\hline$>80$ & 902 & 8.2 \\
\hline \multicolumn{3}{|l|}{ Sex } \\
\hline Male & 5862 & 53.0 \\
\hline Female & 5195 & 47.0 \\
\hline \multicolumn{3}{|l|}{ Race } \\
\hline White & 7784 & 70.4 \\
\hline Black & 713 & 6.4 \\
\hline Other & 703 & 6.4 \\
\hline Unknown & 1857 & 16.8 \\
\hline \multicolumn{3}{|l|}{ Surgical Indication } \\
\hline Malignant tumor & 3288 & 29.7 \\
\hline Benign tumor & 4995 & 45.2 \\
\hline Tumor Not Otherwise Specified & 1433 & 13.0 \\
\hline Other disease of parotid & 977 & 8.8 \\
\hline Other/unknown & 364 & 3.3 \\
\hline \multicolumn{3}{|l|}{ Comorbidities } \\
\hline Bleeding disorder & 248 & 2.2 \\
\hline Diabetes & 1707 & 15.4 \\
\hline On dialysis & 39 & 0.4 \\
\hline Disseminated cancer & 364 & 3.3 \\
\hline Dyspnea & 536 & 4.8 \\
\hline Dependent functional status & 129 & 1.2 \\
\hline Congestive Heart Failure & 29 & 0.3 \\
\hline Chronic Obstructive Pulmonary Disease & 518 & 4.7 \\
\hline Hypertension & 5019 & 45.4 \\
\hline Obesity (BMI > 30) & 3857 & 39.7 \\
\hline Smoker & 2602 & 23.5 \\
\hline Corticosteroids & 363 & 3.3 \\
\hline Wound infection & 155 & 1.4 \\
\hline Weight loss & 68 & 0.6 \\
\hline \multicolumn{3}{|l|}{ ASA class } \\
\hline 1 (No disturbance) & 990 & 9.0 \\
\hline 2 (Mild disturbance) & 5355 & 48.5 \\
\hline 3 (Severe disturbance) & 4395 & 39.8 \\
\hline 4 (Life threatening) & 307 & 2.8 \\
\hline
\end{tabular}

in $1.7 \%$ of patients, the most common of these being pneumonia $(0.4 \%)$ and urinary tract infection $(0.4 \%)$. The mean length of stay was 1.65 days with an unplanned 30day readmission rate of $2.1 \%$ (Table 3 ). On binary logistic 
Table 2 Operative Characteristics

\begin{tabular}{|c|c|c|}
\hline \multicolumn{3}{|c|}{ Non-Reconstructive Operative Characteristics } \\
\hline & $\mathrm{N}$ & $\%$ \\
\hline \multicolumn{3}{|l|}{ Parotidectomy extent } \\
\hline Total & 3229 & 29.2 \\
\hline Superficial & 7828 & 70.8 \\
\hline \multicolumn{3}{|l|}{ Management of facial nerve } \\
\hline Not dissected & 1683 & 15.2 \\
\hline Dissected and preserved & 8575 & 77.6 \\
\hline Sacrificed & 405 & 3.7 \\
\hline Unknown & 394 & 3.6 \\
\hline \multicolumn{3}{|l|}{ Concurrent procedures } \\
\hline Neck dissection & 2204 & 19.9 \\
\hline Nerve monitoring & 263 & 2.4 \\
\hline \multicolumn{3}{|l|}{ Surgeon specialty } \\
\hline Otolaryngology & 10,094 & 91.3 \\
\hline General Surgery & 745 & 6.7 \\
\hline Plastic Surgery & 180 & 1.6 \\
\hline Other & 38 & 0.3 \\
\hline \multicolumn{3}{|l|}{ Setting } \\
\hline Inpatient & 4130 & 37.4 \\
\hline Outpatient & 6927 & 62.6 \\
\hline Operative time, mean [SD] (min) & $185.3[141.9]$ & \\
\hline \multicolumn{3}{|c|}{ Utilization of Reconstructive Procedures } \\
\hline & $\mathrm{N}$ & $\%$ \\
\hline Free flap & 393 & 3.6 \\
\hline Other volume restoration & 998 & 9.0 \\
\hline Reinnervation & 205 & 1.9 \\
\hline Reanimation & 124 & 1.1 \\
\hline
\end{tabular}

regression, various patient and procedure related characteristics were found to be independently associated with an increased risk of medical and surgical complications. Of the demographic variables assessed, increasing age was found to be significantly associated with increasing risk for overall medical complications but was not associated with surgical complications (Additional file 2 Table S2). Relative to those with a benign neoplasm, patients undergoing parotidectomy for a malignant neoplasm were found to be at significantly higher risk for overall surgical and medical complications as well as reoperation and readmission (Additional file 2 Table S1). Both smoking and COPD (chronic obstructive pulmonary disease) were independently predictive of wound dehiscence and surgical site infection. Of the concurrent procedures examined, only volume restoration procedures were predictive of surgical complications. Free flap procedures were independently associated with the highest risk for overall surgical complications with an odds ratio of 2.87 (Table 4).
Table 3 Complication Rates Following Parotidectomy

\begin{tabular}{lll}
\hline & N & $\%$ \\
\hline Medical Complications, Overall & 186 & 1.7 \\
Cardiac arrest & 13 & 0.1 \\
Myocardial Infarction & 22 & 0.2 \\
Stroke & 24 & 0.2 \\
Reintubation & 35 & 0.3 \\
Ventilator-dependent > 48 h & 27 & 0.2 \\
Sepsis/septic shock & 33 & 0.3 \\
Pneumonia & 49 & 0.4 \\
Pulmonary Embolism & 13 & 0.1 \\
Acute Kidney Injury & 14 & 0.1 \\
Urinary Tract Infection & 43 & 0.4 \\
Deep Vein Thrombosis & 20 & 0.2 \\
Surgical Complications, Overall & 418 & 3.8 \\
Wound disruption & 50 & 0.5 \\
Superficial SSI & 209 & 1.9 \\
Deep SSI & 84 & 0.8 \\
Hemorrhage/Hematoma & 100 & 0.9 \\
Unplanned Readmission & 236 & 2.1 \\
Unplanned Reoperation & 234 & 2.1 \\
Length of Stay, mean [SD] (days) & 1.65 [4.00] \\
\hline & & \\
\hline
\end{tabular}

Neck dissection, reanimation, and reinnervation procedures were not found to significantly increase risk for any measure of postoperative morbidity (Table 5).

$\mathrm{SSI}=$ surgical site infection, $\mathrm{SD}=$ standard deviation.

\section{Discussion}

To date, this is the most robust dataset to evaluate national trends in parotidectomy surgery. The post-parotidectomy complication rates seen here are the most substantial information available to counsel patients with, and are the most thorough and recent data available thus far. There has been a review of the NSQIP data from 2006 to 2011 which evaluated 2919 patients which also reported low rates of medical and surgical complications [6]. In addition to evaluating a newer and larger dataset, the current study is likely to be of increased validity, as NSQIP removed several unreliable outcomes variables from the dataset in 2012 [5]. The data here correspond to existing literature that postparotidectomy medical and surgical complications increase with increasing age $[7,8]$. However, the rate of surgical site complications seen here are lower than that of those reported in some single-center studies [9], which highlights the institutional differences in complication rates, and the national average estimated with this study may become an important standard for quality of care assessments at an institutional level. The difference in complication rates is an important feature for further investigation as comparison of 
Table 4 Multivariable Logistic Regression of Adverse Events Following Parotidectomy, Significant Variables

\begin{tabular}{|c|c|c|c|}
\hline & OR & $95 \% \mathrm{Cl}$ & $p$ \\
\hline \multicolumn{4}{|l|}{ Surgical site infection } \\
\hline Male & 1.41 & $1.01-1.96$ & 0.042 \\
\hline Bleeding disorder & 2.21 & $1.20-4.07$ & 0.011 \\
\hline Diabetes & 1.66 & $1.17-2.37$ & 0.005 \\
\hline COPD & 2.08 & $1.25-3.45$ & 0.005 \\
\hline Hypertension & 1.53 & $1.08-2.16$ & 0.017 \\
\hline Smoking & 1.85 & $1.32-2.59$ & $<0.001$ \\
\hline Malignant tumor & 1.70 & $1.09-2.67$ & 0.021 \\
\hline Free flap reconstruction & 2.87 & $1.67-4.93$ & $<0.001$ \\
\hline Other volume restoration & 1.66 & $1.07-2.57$ & 0.025 \\
\hline \multicolumn{4}{|l|}{ Wound Dehiscence } \\
\hline COPD & 2.65 & $1.03-6.87$ & 0.044 \\
\hline Smoking & 2.58 & $1.23-4.34$ & 0.013 \\
\hline Malignant tumor & 4.33 & $1.36-13.77$ & 0.013 \\
\hline Other disease of parotid & 5.31 & $1.51-18.71$ & 0.009 \\
\hline Free flap reconstruction & 3.25 & $1.39-7.58$ & 0.006 \\
\hline Other volume restoration & 3.39 & $1.60-7.19$ & 0.001 \\
\hline \multicolumn{4}{|l|}{ Hematoma/seroma } \\
\hline Free flap reconstruction & 3.13 & $1.43-6.83$ & 0.004 \\
\hline \multicolumn{4}{|l|}{ Readmission } \\
\hline Disseminated cancer & 2.02 & $1.30-3.15$ & 0.002 \\
\hline Hypertension & 1.44 & $1.05-1.97$ & 0.023 \\
\hline Corticosteroids & 2.62 & $1.69-4.07$ & $<0.001$ \\
\hline Wound infection & 2.07 & $1.10-3.90$ & 0.025 \\
\hline Malignant tumor & 3.00 & $1.94-4.65$ & $<0.001$ \\
\hline Other disease of parotid & 2.21 & $1.31-3.75$ & 0.003 \\
\hline \multicolumn{4}{|l|}{ Reoperation } \\
\hline Bleeding disorder & 1.82 & $1.02-3.26$ & 0.044 \\
\hline Disseminated cancer & 1.66 & $1.01-2.71$ & 0.044 \\
\hline Malignant tumor & 2.64 & $1.65-4.20$ & $<0.001$ \\
\hline Free flap reconstruction & 3.56 & $2.30-5.50$ & $<0.001$ \\
\hline
\end{tabular}

$\mathrm{OR}=$ odds ratio, $\mathrm{Cl}=$ confidence interval.

quality of care becomes increasingly important. While one may assume that high volume centers would have lower complication rates, in parotidectomy for benign disease, a previous study has shown that surgeon experience did not seem to be associated with complication rates- however, at that institution they admit that more complicated cases were reserved for more experienced surgeons [10].

There is a significant body of research available evaluating single-site experiences with common complications after parotidectomy. These studies are mostly limited to facial paresis, Frey syndrome, hypoesthesia, and contour deformity. Unfortunately, this dataset did not capture these complications. However, there is evidence that parotidectomy
Table 5 Multivariable Logistic Regression of Adverse Events Following Parotidectomy: Odds Ratios Associated with Reconstructive Procedures

\begin{tabular}{|c|c|c|c|}
\hline & OR & $95 \% \mathrm{Cl}$ & $p$ \\
\hline \multicolumn{4}{|l|}{ Surgical site infection } \\
\hline Free flap reconstruction & 2.87 & $1.67-4.93$ & $<0.001$ \\
\hline Other volume restoration & 1.66 & $1.07-2.57$ & 0.025 \\
\hline Reinnervation & 0.93 & $0.42-2.22$ & 0.961 \\
\hline Reanimation & 0.94 & $0.35-2.62$ & 0.959 \\
\hline \multicolumn{4}{|l|}{ Wound Dehiscence } \\
\hline Free flap reconstruction & 3.25 & $1.39-7.58$ & 0.006 \\
\hline Other volume restoration & 3.39 & $1.60-7.19$ & 0.001 \\
\hline Reinnervation & 0.47 & $0.12-2.66$ & 0.563 \\
\hline Reanimation & 1.90 & $0.50-7.25$ & 0.350 \\
\hline \multicolumn{4}{|l|}{ Hemorrhage/Hematoma } \\
\hline Free flap reconstruction & 3.13 & $1.43-6.83$ & 0.004 \\
\hline Other volume restoration & 1.02 & $0.46-2.27$ & 0.962 \\
\hline Reinnervation & 0.42 & $0.12-2.46$ & 0.537 \\
\hline Reanimation & 2.11 & $0.63-7.05$ & 0.227 \\
\hline \multicolumn{4}{|l|}{ Readmission } \\
\hline Free flap reconstruction & 1.29 & $0.72-2.32$ & 0.399 \\
\hline Other volume restoration & 1.24 & $0.79-1.97$ & 0.353 \\
\hline Reinnervation & 0.72 & $0.28-1.86$ & 0.493 \\
\hline Reanimation & 1.18 & $0.44-3.18$ & 0.749 \\
\hline \multicolumn{4}{|l|}{ Reoperation } \\
\hline Free flap reconstruction & 3.56 & $2.30-5.50$ & $<0.001$ \\
\hline Other volume restoration & 1.50 & $0.95-2.38$ & 0.083 \\
\hline Reinnervation & 1.03 & $0.51-2.07$ & 0.937 \\
\hline Reanimation & 1.30 & $0.62-2.72$ & 0.481 \\
\hline
\end{tabular}

reconstructive techniques may mitigate some of these adverse outcomes.

Facial paresis following parotidectomy is a common finding that is typically self-limiting and limited to marginal mandibular nerve weakness [11]. This risk may be mitigated by performing a limited surgical approach [12-14], or if there is reconstruction with a muscular flap, with or without an abdominal fat graft $[15,16]$. Frey syndrome is a historically common complication following parotidectomy described as gustatory sweating due to aberrant reinnervation of secretory parasympathetic fibers from parotid tissue to dermal tissue. Reconstructive procedures that provide a barrier between parotid tissue and the dermal surface have been shown to decrease the incidence of Frey Syndrome [15, 17-20]. These reconstructions include rotating a sternocleidomastoid flap into the defect, elevating a superficial musculoaponeurotic flap prior to performing parotidectomy, grafting free abdominal fat, and insertion of acellular 
dermis. There is continued debate on the most effective reconstruction method. A meta-analysis on the subject suggests that all of the above interventions decrease Frey syndrome but acellular dermis implants may be associated with higher infection rates [14].

These reconstruction options also help improve postoperative facial symmetry, especially in cases of total parotidectomy. Parotidectomy, as a common procedure performed in a highly cosmetic region is uniquely poised to benefit from advances in maintaining symmetric volume and minimizing visible scarring. Adequate exposure and improved scar cosmesis has been shown to follow from the trend of utilizing a facelift incision in parotidectomy $[21,22]$. Following large parotidectomy defects encountered in total parotidectomy and radical parotidectomy, muscular flaps and fat grafting have shown to reduce contour asymmetry $[16,22,23]$. Additionally, another level of complexity occurs when parotidectomy requires concurrent skin and/ or facial nerve sacrifice which typically is necessary in cases of malignant lesions with adjacent tumor invasion. Fortunately, multiple reconstructive options exist for these defects- for skin and soft tissue reconstruction, anterolateral thigh free flaps have been the mainstay of treatment due to the large vessel caliber available for microvascular anastomosis and variable size and shape available with this option [24-27]. Additionally, if the patient requires postoperative radiation, the volume of this free flap after radical parotidectomy reconstruction has been shown to be reduced by only $8 \%$ [28]. Other options available for free flap reconstruction include latissimus dorsi free flap and superficial inferior epigastric artery free flap [29]. However, the latissimus dorsi free flap is more difficult to harvest concurrently and is likely to result in higher postoperative donor site morbidity. The superficial inferior epigastric artery free flap has much smaller caliber vessels which may increase risk of flap failure and decrease ability for postoperative flap monitoring. For cases with facial nerve sacrifice, it is surprising that only $25.5 \%$ of patients have documented reinnervation procedures, and only $24 \%$ have documented reanimation procedures (Table 2). This low rate of facial reinnervation and reanimation following radical parotidectomy is also underscored in a recent review of NSQIP [30]. This leads to the question of whether these procedures fail to be coded and thus detected by the database or whether these procedures are truly not performed commonly in cases with facial nerve sacrifice. There is encouraging data that would encourage immediate reinnervation and reanimation in these cases [31].

Surgical site infection following parotidectomy is not a well-researched complication, likely due to its low incidence. Our study showed an incidence of $2.7 \%$, with the highest predictors of SSI being concurrent free flap and pre-existing bleeding disorder. This would provide evidence that the mechanism for post-parotidectomy wound infections is from hematoma formation that becomes subsequently infected. Following this logic, as post-parotidectomy hematomas are more common in males due to rich blood supply of hair follicles in the overlying dermis, it is not surprising that males were also found to have significantly increased risk for developing SSI compared to females. In fact, in the literature, there been an association with drain output greater than $50 \mathrm{ml}$ in $24 \mathrm{~h}$ to be predictive of surgical site infection [32, 33]. Since abdominal fat grafts have also been shown to be associated with increased surgical site drainage [20] and larger defects are more likely to prompt contour adjustments, it is concordant that volume restoration was associated with a higher rate of SSIs in our dataset (Table 4).

Poor wound-healing may also contribute to SSI and wound dehiscence and this process may be exacerbated by the systemic factors seen to increase risk for both of these outcomes in this study. These factors include comorbid COPD, diabetes, and a smoking history. These results contradict a recent single-center study which did not find an association with diabetic status and post-parotidectomy surgical site infection [34]. However, they are consistent with previous data on smoking increasing surgical complication risk following parotidectomy [6]. Many institutions, including our own, preoperatively counsel patients on the importance of smoking cessation prior to parotidectomy and this study provides substantiated data to help further justify and aid this counseling process.

Medical complications that do not involve the surgical site are not well-studied and the data provided here point towards a relatively low incidence of these adverse outcomes. These complications appear to be associated with advanced age, malignancy, weight loss, wound infection, concomitant corticosteroid use, free flap reconstruction, and undergoing surgery in an inpatient setting (Additional file 2 Table S2). These associated factors are unsurprising as older patients and those who have malignancy or require free flap reconstruction would be expected to be at an elevated risk preoperatively and those with a higher ASA (American Society of Anesthesiologists) physical status level would be more likely to have their surgery performed at a hospital-based setting.

\section{Limitations}

This study is subject to several limitations inherent to the use of a large national database. The most notable of these is the absence of procedure-specific outcomes such as facial nerve paresis and the inability to assess complications beyond the 30-day postoperative period. There is also the issue of procedures that are not coded correctly. For example, in this dataset, facial nerve monitoring was 
only coded in $2.4 \%$ of cases, despite this being a routine aspect of parotidectomy and is considered by many surgeons to be the standard of care. The small incidence of facial nerve monitoring in this study is likely due to lack of proper documentation and exemplifies a fundamental limitation of using this retrospective dataset. Further, the possibility of confounding cannot be excluded given the absence of disease-specific variables such as tumor stage. However, the data captured by NSQIP has been shown to be of high validity, particularly when compared to comparable population datasets derived from administrative claims data [35]. The method of data collection is worth noting, as NSQIP is unique in utilizing trained clinical reviewers to extract data from the medical record. As a result, NSQIP data has been shown to capture $61 \%$ more complications than comparable population datasets derived from administrative claims data [35]. However, this method of data collection may in part explain the lower than expected rate of concurrent procedures such as nerve monitoring, as the associated CPT code may not have been clearly documented in the medical record. While the strength of this analysis lies in the statistical power afforded by the NSQIP database, these results should be interpreted with these limitations in mind.

\section{Conclusions}

As the US health care system moves towards a qualitybased outcome model, the information available in this data set regarding readmission and reoperation rates are of importance for risk-stratification of these patients. Not only surgeons, but hospital administrators will be interested in readmission rates for this relatively safe procedure. Thus, being aware of these variables (Table 4) may help with patient selection for inpatient versus outpatient surgery as well as frequency and duration of follow up for patients with these identified risk factors. Further study is necessary to determine the cause of readmission and reoperation for these patients and whether these readmissions are avoidable.

\section{Supplementary information}

Supplementary information accompanies this paper at https://doi.org/10. 1186/s40463-019-0387-y.

Additional file 1: Table S1. Descriptive Variables Derived from Billing Codes (DOCX $16 \mathrm{~kb}$ )

Additional file 2: Table S2. Multivariable Logistic Regression, Overall Complications (DOCX $29 \mathrm{~kb}$ )

\section{Abbreviations}

ACS: American College of Surgeons; ASA: American Society of Anesthesiologists; BMI: body mass index; COPD: chronic obstructive pulmonary disease; CPT: Current Procedural Terminology; ICD: International Classification of Disease; NOS: not otherwise specified; NSQIP: National
Surgical Quality Improvement Program; SPSS: Statistical Package for the Social Sciences; SSI: surgical site infection

\section{Acknowledgments}

Not applicable.

\section{Author's contributions}

CB contributed to study conception, design, data analysis and data interpretation, was the main contributor to writing of the manuscript and subsequent edits, and is the corresponding and first author. All authors read and approved the final manuscript. PC contributed to study conception, design, data analysis, and data interpretation. PC contributed much preliminary data and wrote the first draft of the abstract. PC was the main contributor to manuscript edits. MC was the main contributor to data analysis and constructed the tables in the paper. MC was a significant contributor to manuscript preparation. JC contributed substantially to study design, data interpretation, manuscript editing, and overall goals of the paper. HK contributed substantially to study design, data interpretation, manuscript editing, and overall goals of the paper. RH contributed substantially to study design, data interpretation, manuscript editing, and overall goals of the paper.

Funding

There were no sources of funding for this research.

\section{Availability of data and materials}

The NSQIP dataset used in this study are available via the American College of Surgeons website: https://www.facs.org/quality-programs/acs-nsqip/ participant-use/puf-form.

\section{Ethics approval and consent to participate}

This analysis was determined to be exempt from Institutional Review Board approval due to the de-identified nature of the dataset.

Consent for publication

Not applicable.

\section{Competing interests}

The authors declare that they have no competing interests.

Received: 2 July 2019 Accepted: 22 October 2019

Published online: 19 November 2019

References

1. Lewis AG, Tong T, Maghami E. Diagnosis and management of malignant salivary gland tumors of the parotid gland. Otolaryngol Clin N Am. 2016; 49(2):343-80,

2. Koch M, Zenk J, Iro H. Long-term results of morbidity after parotid gland surgery in benign disease. Laryngoscope. 2010;120(4):724-30.

3. Farwell DG, Reilly DF, Weymuller EA Jr, Greenberg DL, Staiger TO, Futran NA. Predictors of perioperative complications in head and neck patients. Archives of Otolaryngology-Head \& Neck Surgery. 2002;128(5):505-11.

4. Nitzan D, Kronenberg J, Horowitz Z, et al. Quality of life following parotidectomy for malignant and benign disease. Plast Reconstr Surg. 2004; 114(5):1060-7.

5. User Guide for the 2012 ACS NSQIP Participant Use Data File. American College of Surgeons National Surgical Quality Improvement Program; 2013.

6. Kim BD, Lim S, Wood J, Samant S, Ver Halen JP, Kim JYS. Predictors of adverse events after parotidectomy: a review of 2919 cases. Annals of Otology, Rhinology \& Laryngology. 2015;124(1):35-44.

7. Bohatch Júnior MS, Mendes RA, da-Silva AFV, Lorenzini MS, Dohler AW, Graciano AJ. Evaluation of postoperative complications in elderly patients submitted to parotidectomy. Revista do Colégio Brasileiro de Cirurgiões. 2018;45(4).

8. Ruohoalho J, Mäkitie AA, Aro K, et al. Complications after surgery for benign parotid gland neoplasms: a prospective cohort study. Head \& Neck. 2017; 39(1):170-6

9. Romano A, Cama A, Corvino R, et al. Complications after parotid gland surgery our experience. Ann Ital Chir. 2017;88:295-301. 
10. Guntinas-Lichius O, Klussmann JP, Wittekindt C, Stennert E. Parotidectomy for benign parotid disease at a university teaching hospital: outcome of 963 operations. Laryngoscope. 2006;116(4):534-40.

11. Infante-Cossio P, Gonzalez-Cardero E, Garcia-Perla-Garcia A, Montes-Latorre E, Gutierrez-Perez JL, Prats-Golczer VE. Complications after superficial parotidectomy for pleomorphic adenoma. Medicina oral, patologia oral y cirugia bucal. 2018;23(4):e485-92.

12. Plaza G, Amarillo E, Hernández-García E, Hernando M. The role of partial parotidectomy for benign parotid tumors: a case-control study. Acta Otolaryngol. 2015;135(7):718-21.

13. Kilavuz AE, Songu M, Pinar E, Ozkul Y, Ozturkcan S, Aladag I. Superficial Parotidectomy versus partial superficial Parotidectomy: a comparison of complication rates, operative time, and hospital stay. J Oral Maxillofac Surg. 2018;76(9):2027-32.

14. Upton DC, McNamar JP, Connor NP, Harari PM, Hartig GK. Parotidectomy: ten-year review of 237 cases at a single institution. Otolaryngol Head Neck Surg. 2007;136(5):788-92.

15. Curry JM, Fisher KW, Heffelfinger RN, Rosen MR, Keane WM, Pribitkin EA. Superficial Musculoaponeurotic system elevation and fat graft reconstruction after superficial Parotidectomy. Laryngoscope. 2008;118(2): 210-5.

16. Curry JM, King N, Reiter D, Fisher K, Heffelfinger RN, Pribitkin EA. Metaanalysis of surgical techniques for preventing Parotidectomy Sequelae. Arch Facial Plast Surg. 2009;11(5):327-31

17. Wang S, Li L, Chen J, et al. Effects of free fat grafting on the prevention of Frey's syndrome and facial depression after parotidectomy: a prospective randomized trial. Laryngoscope. 2016; 126(4):815-9.

18. Baum SH, Pförtner R, Ladwein F, Schmeling C, Rieger G, Mohr C. Use of dermis-fat grafts in the prevention of Frey's syndrome after parotidectomy J Cranio-Maxillofac Surg. 2016;44(3):301-8.

19. Dulquerov N, Makni A, Dulquerov P. The superficial musculoaponeurotic system flap in the prevention of Frey syndrome: a meta-analysis. Laryngoscope. 2016;126(7):1581-4.

20. Wang C, Wu D. Mao C, et al. Journal of Cranio-Maxillofacial Surgery: The preventive effect of decellularized pericardial patch against Frey's syndrome following the superficial parotidectomy; 2019.

21. Grover N, D'Souza A. Facelift approach for Parotidectomy: an evolving aesthetic technique. Otolaryngol Head Neck Surg. 2013;148(4):548-56.

22. Bianchi B, Ferri A, Ferrari S, Copelli C, Sesenna E. Improving esthetic results in benign parotid surgery: statistical evaluation of facelift approach, sternocleidomastoid flap, and superficial Musculoaponeurotic system flap application. J Oral Maxillofac Surg. 2011;69(4):1235-41.

23. Loyo M, Gourin CG. Free abdominal fat transfer for partial and total parotidectomy defect reconstruction. Laryngoscope. 2016;126(12):2694-8.

24. Cannady SB, Seth R, Fritz MA, Alam DS, Wax MK. Total parotidectomy defect reconstruction using the buried free flap. Otolaryngol Head Neck Surg. 2010;143(5):637-43.

25. Ch'ng S, Ashford BG, Gao K, McGuinness J, Clark JR. Reconstruction of postradical parotidectomy defects. Plastic and reconstructive surgery. 2012; 129(2):275e-287e

26. Elliott RM, Weinstein GS, Low DW, Wu LC. Reconstruction of complex total parotidectomy defects using the free anterolateral thigh flap: a classification system and algorithm. Ann Plast Surg. 2011;66(5):429-37.

27. Ciolek PJ, Prendes BL, Fritz MA. Comprehensive approach to reestablishing form and function after radical parotidectomy. Am J Otolaryngol. 2018;39(5): $542-7$.

28. Higgins KM, Erovic BM, Ravi A, et al. Volumetric changes of the anterolateral thigh free flap following adjuvant radiotherapy in total parotidectomy reconstruction. Laryngoscope. 2012;122(4):767-72.

29. Alkureishi LWT, Bhayani MK, Sisco M. Superficial inferior Epigastric artery flap for a Total Parotidectomy defect. Eplasty. 2017;17:e38

30. Lu GN, Villwock MR, Humphrey CD, Kriet JD, Bur AM. Analysis of facial reanimation procedures performed concurrently with Total Parotidectomy and facial nerve sacrifice. JAMA Facial Plastic Surgery. 2019;21(1):50-5

31. Sánchez-Burgos R, Otero TG, Lassaletta L, Arias Gallo J, Cuellar IN, García MB Facial nerve reconstruction following radical parotidectomy and subtotal petrosectomy for advanced malignant parotid neoplasms. Annals of maxillofacial surgery. 2015:5(2):203-7.
32. Shkedy $Y$, Alkan $U$, Roman BR, et al. Role of perioperative antibiotic treatment in parotid gland surgery. Head \& Neck. 2016:38(S1):E1876-80.

33. Meccariello G, Montevecchi F, D'Agostino G, et al. Surgical site infections after parotidectomy: management and benefits of an antibiotic prophylaxis protocol. Acta Otorhinolaryngol Ital. 2018.

34. Ziegler A, Teng S, Thorpe E. Body Mass Index and Parotidectomy Outcomes. Journal of Craniofacial Surgery. 2019;30(1).

35. Steinberg SM, Popa MR, Michalek JA, Bethel MJ, Ellison EC. Comparison of risk adjustment methodologies in surgical quality improvement. Surgery. 2008/10/01/ 2008;144(4):662-669

\section{Publisher's Note}

Springer Nature remains neutral with regard to jurisdictional claims in published maps and institutional affiliations.
Ready to submit your research? Choose BMC and benefit from:

- fast, convenient online submission

- thorough peer review by experienced researchers in your field

- rapid publication on acceptance

- support for research data, including large and complex data types

- gold Open Access which fosters wider collaboration and increased citations

- maximum visibility for your research: over $100 \mathrm{M}$ website views per year

At BMC, research is always in progress.

Learn more biomedcentral.com/submissions 